\title{
Rehabilitation of storm water collection systems of urban environment using the small roads as conveyance channels
}

\author{
Ş. Tiğrek $\cdot$ S. O. Sipahi
}

Received: 6 January 2011 / Revised: 12 July 2011/ Accepted: 2 September 2011/Published online: 8 December 2011

(c) CEERS, IAU 2011

\begin{abstract}
In this study a new grated inlet is proposed for small roads which do not have storm water collection systems. A setup was designed and constructed in the laboratory conditions to calibrate the grated inlet. The inlet is suggested to be installed at the end of the road where the road itself joins to another road or to a street. Thus, newly installed inlet will collaborate with existing storm water collecting system of the main road. Inlet structure covered by slots is installed across a $0.90-\mathrm{m}$ wide flume which will act as a small road. The slots are longitudinal and parallel to the flow direction in order to curtail clogging. It is a tilting flume and both subcritical and supercritical flow regimes can be observed. The intercepted flow by the inlet is measured and the efficiency of the inlet is obtained in terms of longitudinal slope and the Froude number. It is observed that the grate efficiency gets higher as the longitudinal slope approaches to horizontal. Further the grate efficiency also depends on the total flow through the channel. As flow increases in the channel, the efficiency of the grate increases within the limit of the inlet or discharge channels capacity.
\end{abstract}

Keywords Inlet efficiency - Intercepted flow · Bypass flow $\cdot$ Storm water $\cdot$ Urban drainage

\section{Introduction}

The reason of the migration from rural areas to urban areas can be several and the consequent outcomes can vary

Ş. Tiğrek $(\bowtie) \cdot$ S. O. Sipahi

Hydraulic Division, Civil Engineering Department,

Middle East Technical University, Ankara, Turkey

e-mail: sahnaz@metu.edu.tr largely. Its impact on infrastructure is huge especially in developing countries. It is not unusual that the city enlargement is not aligned with the development of the infrastructure. One can observe very often that a much bigger city without infrastructure and proper planning grows at the outskirts of the well-planned core. Today due to the adverse effects of climate change, many big cities face severe damages due to heavy storms. Flooding occurs due to either a heavy storm that exceeds the design criteria of the structure or inadequate capacity (Thompson et al. 2003). Usually drainage of storm water has stayed on the bottom of service list. Cities covered with concrete and asphalt allow water to occupy the city roads and even cause flood in the settlements. Furthermore, water flowing on a road may cause traffic accidents (Guo 2000).

Storm water collection systems must be properly designed to provide necessary surface drainage and should meet other storm water management goals such as water quality (Nabizadeh et al. 2005) stream bank channel protection; habitat protection and groundwater recharge (Thompson et al. 2003). Nevertheless in many big cities, it is nearly impossible to establish underground water collection system to all extent. Therefore in the present study, it is suggested that the excess water will be collected at the end of a small road from where it will be diverted to the main collecting system or underground storage systems. This procedure can find a place under the title of low Impact development (LID); although low impact development does not promote to install grates, it enables the water to infiltrate as much as possible to a location near to the source (EPA 2000, 2007). However, big cities of developing countries lost their chances to return to their old natural habitats. Today those cities face a big challenge to improve, rehabilitate, renovate or even re-establish their infrastructures. 
This is quite costly and needs proper engineering services too. By all means financial burden of the rehabilitation of storm water drainage system will cost a huge amount for developed countries like USA (Rens 2007) too. However, it is possible to rehabilitate collection system of the main streets by replacing them with larger capacities and using the small roads as the conveyance channels themselves. By this way these roads can be paved by permeable surface cover (EPA 2007) and the water which does not infiltrate can be collected by a grate installed at the end of the road. This will be a solution to local flooded areas and the procedure may be re-addressed as partial LID in big cities.

The principals of the major hydraulic components in a storm water drainage system are as follows: inlets, conduits, junctions, manholes, and outfall structures. All the components have equal importance and need proper design specifications in terms of hydraulic engineering.

The flow through an inlet on the bottom of the channel (bottom intake racks) is often used as flow outlet which finds application in irrigation channels to purge excess water, trash racks on small mountain rivers and urban drainage system to carry away rain water (grated inlet), (Chow 1959; Ramamurthy et al. 1989; Subramanya 1994; Brunella et al. 2003; Righetti and Lanzoni 2008).

The flow in bottom racks and grates is the case of spatially varied flow with decreasing discharge in the flow direction. The dynamics of the flow over the rack and the determination of the discharge through the rack have been attacked by many researchers. Although, it is a threedimensional problem, it is assumed as one-dimensional flow with negligible energy losses in practical applications (Akan 2000; Righetti and Lanzoni 2008). Actually there is deviation from hydrostatic pressure (Mostkow 1957) and there is streamline curvature (Righetti and Lanzoni 2008). There are attempts to solve the problem analytically and experimentally (Mostkow 1957; Noseda 1955; Subramanya 1994; Brunella et al. 2003; Righetti and Lanzoni 2008). Yet most of the researches were based on the experimental findings. Further both trash racks and grated inlet are covered with bars, parallel, longitudinal or reticulate, etc. These bars also affect the flow dynamics (Gomez and Russo 2005, 2009, 2011). Due to all these reasons the grates are calibrated through laboratory studies (Woo and Jones 1974; Kranc and Anderson 1993; Brown et al. 1996; Thomas 1999; Guo 2000; Gomez and Russo 2005, 2009, 2011). Beecham et al. (2006) have conducted experimental study to analyze frictional effect on spatially varied flow. Thomas (1999) discussed practical difficulties involved, such as application to non-uniform gutter profile. Heggen (1989) studied inaccuracies of equations for the spatially varying flow from Chow (1959). Studies focusing on grate inlet interception capacity are rather less in the literature.
Woo and Jones (1974) carried out experiments to make suggestions on both the hydraulic capacity and safety of the inlets for bicycle riders by trying inlets with different tilting angles. Kranc and Anderson (1993) have investigated the influence of grates on the overall inlet performance. Brown et al. (1996) listed the grate types for which design procedures were developed. Guo (2000) presented an investigation on street hydraulic capacity. It was found that the street storm water capacity at a sump is in fact dictated by the storage capacity rather than the conveyance capacity. In their study Gomez and Russo tried to formulate the efficiency in terms of the discharge and the upstream depth. (Gomez and Russo 2005, 2009, 2011).

In the present study, an experimental setup is developed to observe the flow interception rate through a grated inlet installed in a tilting flume. The setup is designed by modifying existing tilting steel channel in the Hydromechanics Laboratory of the Middle East Technical University of Ankara, Turkey.

\section{Materials and methods}

\section{Dimensionless analysis}

Figure 1 shows a schematic view of the flow through bottom outlets (bottom racks, grated inlets, etc.) in general.

In Fig. $1 x$ and $y$ denote the axis along the flow direction and the gravitational direction, respectively. $E[\mathrm{~L}]$ is the specific energy at the head of the outlet. $y_{1}[\mathrm{~L}]$ and $y_{2}[\mathrm{~L}]$ are the flow depths at the upstream and downstream of an outlet having a length of $l[\mathrm{~L}]$, respectively. The discharge of a partial withdrawal from the main flow through a bottom outlet, namely, intercepted flow, $Q_{\mathrm{I}},\left[\mathrm{L}^{3} / \mathrm{T}\right]$ can be expressed as the difference between bypassed flow, $Q_{\mathrm{B}}\left[\mathrm{L}^{3} / \mathrm{T}\right]$ and the total channel flow, $Q_{\mathrm{T}}$,

$Q_{\mathrm{I}}=Q_{\mathrm{T}}-Q_{\mathrm{B}}$.

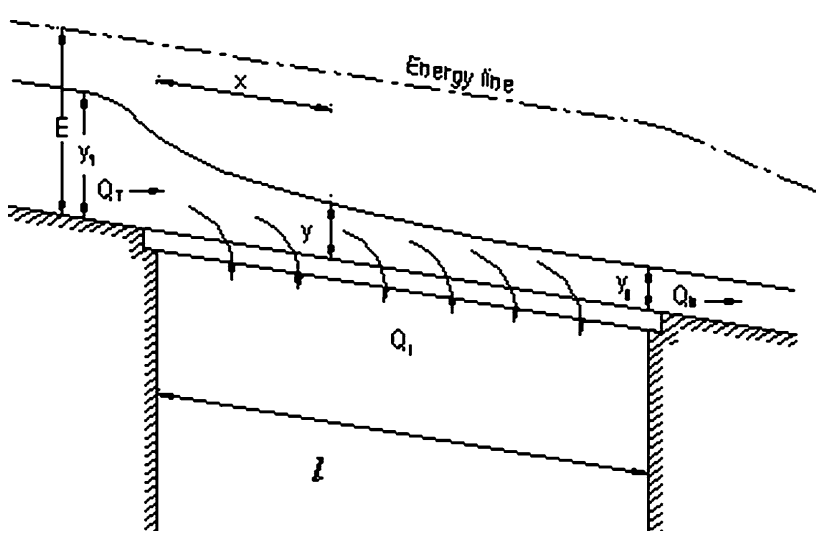

Fig. 1 Water flowing over a bottom outlet 
Chow (1959) describes the flow intercepted as a function of flow depths and the specific energy, $E$. However, in these kinds of formulations the water depths at the upstream and downstream of the inlet should be measured. This can be an easy task for the bottom racks; however in case of rain water inlet, the precise measurements are quite difficult due to very small water depth values, especially at the downstream. Therefore, a parametric analysis is preferred instead of scrutinizing the flow dynamics. The intercepted flow can be written as a function of 12 variables as depicted below,

$Q_{\mathrm{I}}=f_{1}\left(Q_{\mathrm{T}}, y_{1}, w, k_{\mathrm{s}}, g, \rho, v, d_{1}, d_{2}, d_{3}, S, S_{\mathrm{r}}\right)$

where, $w[\mathrm{~L}]$ is width of the channel; $k_{\mathrm{S}}[\mathrm{L}]$ roughness height; $g\left[\mathrm{~L} / \mathrm{T}^{2}\right]$ gravitational acceleration; $v\left[\mathrm{~L}^{2} / \mathrm{T}\right]$ kinematic viscosity of the water; $\rho\left[\mathrm{M} / \mathrm{L}^{3}\right]$ density of the water and $d_{1}, d_{2}, d_{3}[\mathrm{~L}]$ are several geometric parameters associated with bottom outlets. $S$ [ ] and $S_{\mathrm{r}}$ [ ] are the longitudinal and cross slopes, respectively. The Buckhingham $\pi$ theorem (Munson et al. 1998) will give nine $\pi$ terms; if one selects $\rho$, $Q_{\mathrm{T}}$ and $\mathrm{y}_{1}$ as repeated variables:

$\pi_{o}=f_{2}\left(\pi_{1}, \pi_{2}, \pi_{3}, \pi_{4}, \pi_{5}, \pi_{6}, \pi_{7}, \pi_{8}, \pi_{9}\right)$

$\frac{Q_{\mathrm{I}}}{Q_{\mathrm{T}}}=f_{3}\left(\frac{y_{1}^{5} g}{Q_{\mathrm{T}}^{2}}, \frac{y_{1} v}{Q_{\mathrm{T}}}, \frac{w}{y_{1}}, \frac{k_{\mathrm{s}}}{y_{1}}, \frac{d_{1}}{y_{1}}, \frac{d_{2}}{y_{1}}, \frac{d_{3}}{y_{1}}, S, S_{\mathrm{r}}\right)$

If the first $\pi$ term is multiplied by the third one, reciprocal of the result will give square of the Froude number, $F^{2}$ as expressed below:

$\pi_{10}=\frac{1}{\pi_{1}} *\left(\frac{1}{\pi_{3}}\right)^{2}=\frac{Q^{2}}{g y_{1}^{3} w^{2}}=F^{2}$

and the reciprocal of the multiplication of second and third $\pi$ terms will give the Reynolds number, $R$, as shown below:

$\pi_{11}=\frac{1}{\pi_{2}} *\left(\frac{1}{\pi_{3}}\right)=\frac{Q_{T}}{y_{1} v}=R$

Thus, the Froude number, $F$ will be summarized as a function of upstream water depth (uniform flow depth), $y_{1}$ and the total discharge, $Q_{\mathrm{T}}$ as follows:

$F=\frac{Q_{\mathrm{T}}}{\sqrt{9.81 w^{2} y_{1}^{3}}}$

Further if the efficiency, $\varepsilon$ is described as the ratio of the intercepted flow to the total flow (FHWA 2001), then it is expressed as:

$\varepsilon=\frac{Q_{\mathrm{I}}}{Q_{\mathrm{T}}}$

Thus $\pi_{o}=Q_{\mathrm{I}} / Q_{\mathrm{T}}$ will be equal to the efficiency, $\varepsilon$, thus the efficiency of a bottom outlet will be represented in terms of nine dimensionless variables as described below:
$\varepsilon=f_{3}\left(F, R, \frac{w}{y_{1}}, \frac{k_{\mathrm{s}}}{y_{1}}, \frac{d_{1}}{y_{1}}, \frac{d_{2}}{y_{1}}, \frac{d_{3}}{y_{1}}, S, S_{\mathrm{r}}\right)$

In the following sections, to determine the efficiency of a bottom outlet, a new experimental setup and preliminary experiments associated with results and discussions will be demonstrated.

Design and calibration of setup

The setup consists of four main units. The first one is the main channel which acts as a road. The second is the inlet system, which consists of grates and storage boxes under the grates. The third one is discharge system and the fourth one is the discharge measurement system.

A new Plexiglas (acrylic sheet) channel is implanted on the existing steel channel. The width of the steel channel is $1.00 \mathrm{~m}$ and the length of the channel is $12.00 \mathrm{~m}$. The channel slope is regulated by a screw; the channel slope can be adjusted to maximum slope of 1/9.22 and to maximum adverse slope of $-1 / 41.80$. Water is supplied from the constant head tank of the laboratory through two $0.20-\mathrm{m}$ pipes, which are regulated by valves. To the upstream of the channel, a screen-type energy dissipater is placed to maintain uniform flow. The width of the new Plexiglas flume is designed as $0.90 \mathrm{~m}$, having $5 \mathrm{~cm}$ spacing from both sides. The height of the implanted flume is $0.45 \mathrm{~m}$. Further, the channel is divided into two stories by a slab. The upper story which will simulate the road has a depth of $0.10 \mathrm{~m}$ and the lower story has a depth of $0.35 \mathrm{~m}$. Lower story is used to install storage box of the inlets. The details can be seen in Fig. 2 .

The grated inlet is located $9 \mathrm{~m}$ apart from the head of the channel as depicted in Fig. 3. The geometric characteristics of the grate for the first series are shown in Fig. 4. The lower portion of the first $9 \mathrm{~m}$ of the channel is supported by the bottom with the help of the beams made of Plexiglas sheets of $0.010-\mathrm{m}$ thickness. The beams are placed with an interval of $0.25 \mathrm{~m}$. Each beam of the five forms a $1.00-\mathrm{m}$ block which is constructed as separate

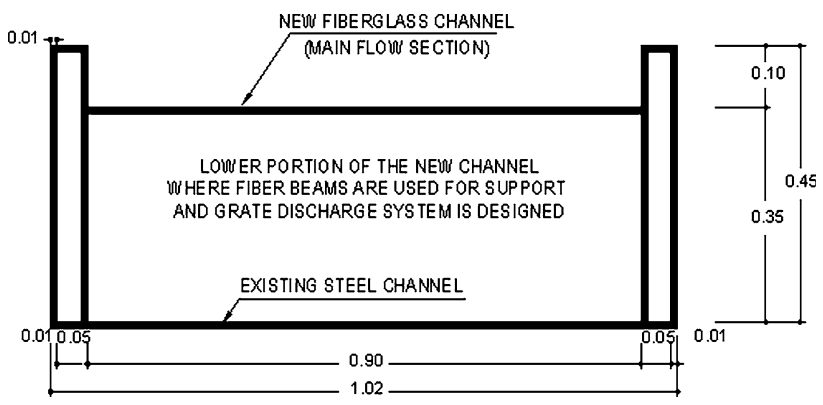

Fig. 2 Cross sectional view of the main channel with the upper and lower stories 


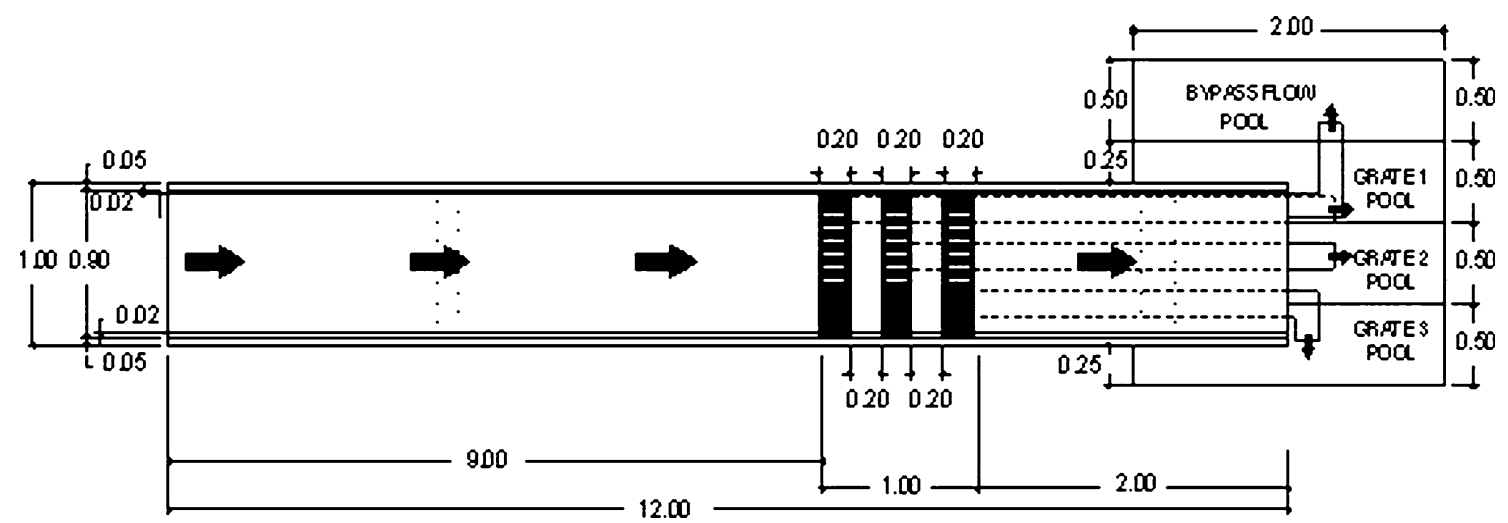

Fig. 3 Top view channel system
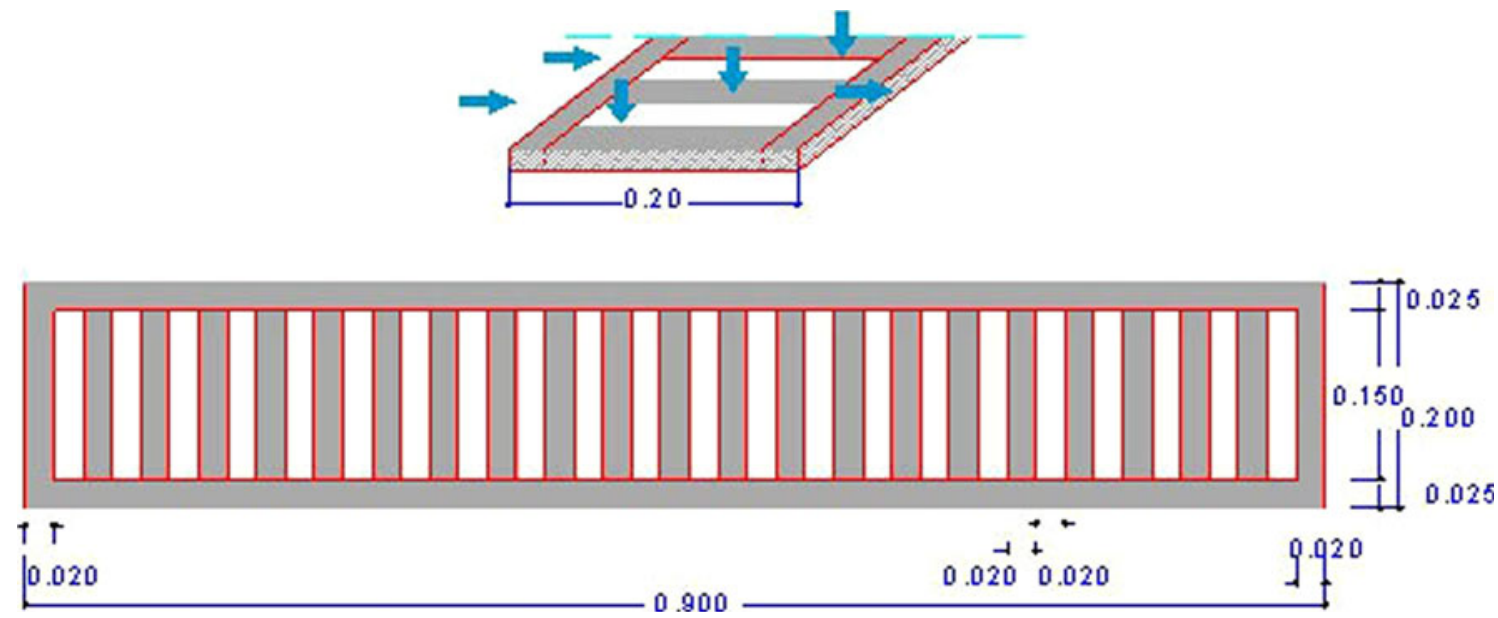

Fig. 4 Grate details

units. The block is fixed to the existing steel channel after precise measurement in order to maintain smooth and uniform surface. For preventing flow leakage between each $1.00 \mathrm{~m}$ portion, special cement is pasted through the slab where two blocks were connected. It should be noted that, the cement used for this purpose is subjected to high temperature changes (approximately -20 to $+40^{\circ} \mathrm{C}$ ), therefore cracks on the cement should be checked regularly and fixed if necessary before collecting data from experiments.

Support beams form the inlet boxes at the location of grates. From the box under the grate, intercepted water is carried through a rectangular discharge channel to the measurement pool. The remaining bypassed flow on the upper channel reaches to the location of second grate. In the same way, second and third grates bypassed flow remain in the upper channel and is collected in a separate pool for the flow measurement (Fig. 3). In this study, only the interception characteristics of the first grate is examined. Therefore a Plexiglas plate was installed instead of second and third grates. After this study, the first, second and third grates may be used together, one by one or with any other possible combination. The storage boxes and the measurement pools for the second and third grates are prepared for the future experiments. The discharge channels of each inlet box are independent of each other. The dimensions of the discharge channels are chosen and arranged as depicted in Figs. 5 and 6.

The discharge system and the measurement system are designed to accommodate for three simultaneously operating grates. Therefore, four pools are constructed and installed at the end of the channel in order to collect and

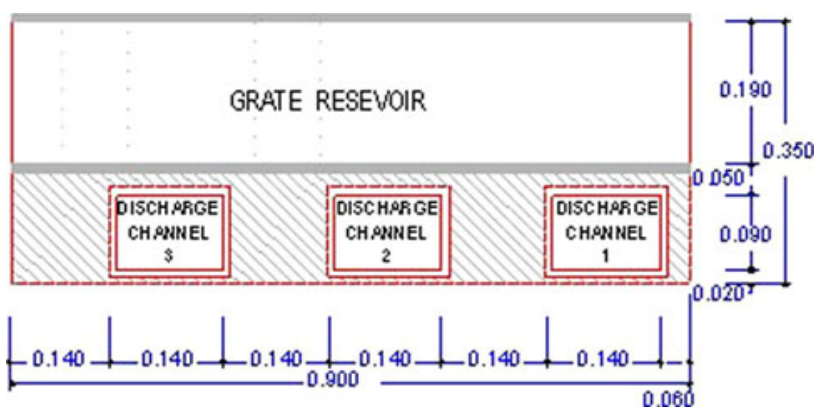

Fig. 5 Cross section of grate reservoir and discharge channels 


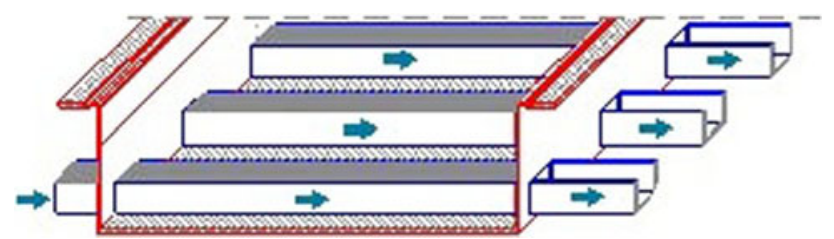

Fig. 6 Isometric view grate discharge channels

measure flow from the inlets and the bypass flow in the main channel (Fig. 7). The downstream conditions of the discharge channels are free outfalls. Each pool has a size of $2.00,0.49$, and $0.60 \mathrm{~m}$. Pools are constructed from $0.015-\mathrm{m}$ thick Plexiglas. A piezometric tube is placed on each pool and a metric scale is placed just on the wall of the pool next to the tube in order to measure the water level in the pool. From the volume of one pool $\left(0.59 \mathrm{~m}^{3}\right)$, for duration of $30 \mathrm{~s}$, the maximum value of $0.0197 \mathrm{~m}^{3} / \mathrm{s}$ of flow rate can be measured. To empty the pools, $5.08 \mathrm{~cm}$ (2 in) diameters of discharge pipes are placed under each pool. The type of the pipe valve is open-close.

Practical application of new grated inlet

There are three distinct differences of the new inlet from the conventional used models:

(a) the inlet is across the entire roadway: in conventional applications grated inlets are located to the side of the roads with certain intervals. Here, new grated inlet is proposed to be installed at the end of small road where the road joining to main road. The roads do not have inlets and underground drainage systems. Thus the roads will act as conveyance channels. The water which is captured by the inlet will join to the storm water collection system of the main road.

(b) The bars of the grate are parallel to the flow direction: in practical application this kind of bar arrangements are not approved due to safety problems for bicycles if the grate is on the way of bicycles. However, for the bicycles which are passing across the road neither bars nor slots will be parallel. Further, in case of decreasing clogging problem, parallel bars are superior to transverse bars. In addition, the occurrence of backwater due to transverse bars can cause traffic accidents.

(c) The road has zero cross slope: a quick examination of super elevation rates given in ASSHTO (2001) can easily lead us to the conclusion that the cross slope of a road can vary between -10 and $+10 \%$. Zero slope can be seen when cross slope changes from negativeto-positive. On the other hand, pavements and parking lots are the areas where only longitudinal slope is seen (Gomez and Russo 2009). Moreover, due to poor constructions, the cross slope may not be applied each time. In addition, it is not a standard procedure for small inner roads in Turkey. Therefore in this study, zero percent cross slope was used on purpose.

Channel capacity determination and rainfall representation

Design and analysis of storm drainage system are based on the Rational formula using the rainfall intensity for a short duration of storm (Pazwash and Boswell 2003). The Rational formula is expressed as (HEC-22 1991):

$Q_{\mathrm{R}}=A_{\mathrm{R}} C I$

where $Q_{\mathrm{R}}$ is the peak flow, $C$ the dimensionless runoff coefficient, $I$ the rainfall intensity and $A_{\mathrm{R}}$ the drainage area $\left(<10 \mathrm{~km}^{2}\right)$. The runoff coefficient, $C$, in Eq. 9 is a function of the ground cover and other hydrologic properties. Typical values for $C$ can be found in Mc Ghee (1991). As a case study of the intensity duration, the occurrence curves of Hopa have been examined, because Hopa, on the coast of the eastern Black Sea, is one of the places that receives the highest rainfall of Turkey. The highest rainfall intensity occurring in 5 min during a 100-year time is about $400 \mathrm{~mm} / \mathrm{h}$ [Source: Turkish State Meteorological Service, TSMS (2008)]. Then the total flow was determined using
Fig. 7 Pools and single pool discharge system
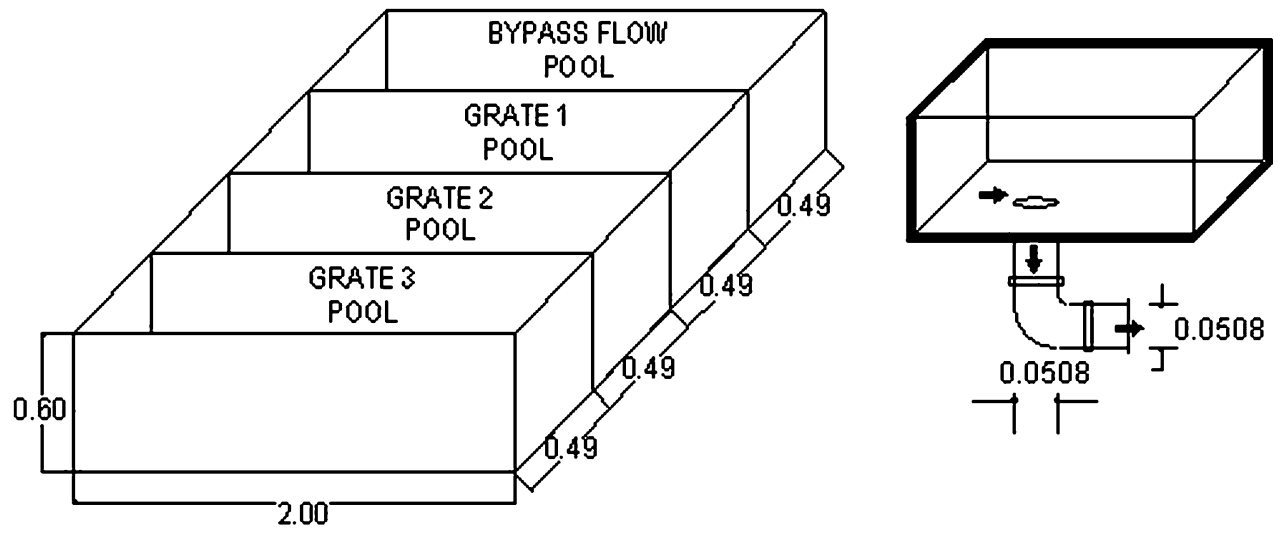
Eq. 9. In the equation, $A_{\mathrm{R}} 8.1 \mathrm{~m}^{2}$. Substituting 0.90 for asphaltic cement street (Mc Ghee 1991) as the value of $C$ and inserting the rainfall intensity, the total surface runoff can be obtained. However, in the laboratory conditions, total flow is supplied through a constant head tank instead of simulating rainfall. Since supply pipes do not have facilities to measure the discharge, the water depth in the channel is used as a measure to control the discharge. Thus, the discharge obtained in Eq. 9 is inserted into the Manning Equation which is expressed in below:

$Q_{\mathrm{R}}=Q_{\mathrm{T}}=\frac{A R_{\mathrm{h}}^{2 / 3} S^{0.5}}{n}$

where, $n$ is the Manning roughness coefficient and taken as 0.010 for Plexiglas. In Eq. $10, A$ is the wetted area and $R_{\mathrm{h}}$ hydraulic radius. Later the flow depth in the channel can be obtained using Eq. 10. A point gauge installed at the flume was used to measure the flow depth within the channel. It is worth mentioning that a natural event where rainfall comes from a basin is represented in the laboratory by providing water from a constant head tank. Table 1 demonstrates corresponding flow depths on six different slopes with a rainfall intensity of $400 \mathrm{~mm} / \mathrm{h}$.

Table 1 Flow depth for various longitudinal slopes resulting in $400 \mathrm{~mm} / \mathrm{h}$ intensity

\begin{tabular}{lll}
\hline$S$ & $y_{1}(\mathrm{~m})$ & $Q\left(10^{-3} \mathrm{~m}^{3} / \mathrm{s}\right)$ \\
\hline $1 / 25$ & 0.00247 & 0.808 \\
$1 / 50$ & 0.00304 & 0.808 \\
$1 / 100$ & 0.00375 & 0.808 \\
$1 / 200$ & 0.00462 & 0.808 \\
$1 / 500$ & 0.00609 & 0.808 \\
$1 / 1000$ & 0.00751 & 0.808 \\
\hline
\end{tabular}

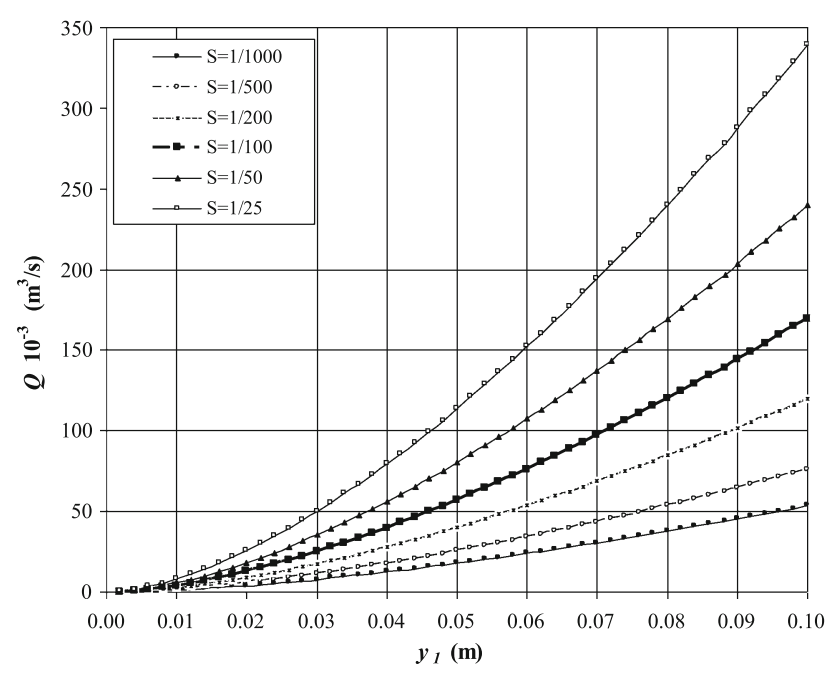

Fig. 8 Channel capacities for different slopes
Figure 8 shows the variation of the channel capacity with the flow depth for six different slopes. By comparing Table 1 and Fig. 8, it can be seen that the channel capacity is much higher than the flow representing Hopa. The depth of flow resulting in $400 \mathrm{~mm} / \mathrm{h}$ intensity is less than $1 \mathrm{~cm}$. In this study starting from sheet flow, higher depths than illustrated shown in the above Table 1 were tested. The higher depth situation can occur in a flood time or in failure of the previous grate inlets in a drainage system which can be seen easily in a daily life.

\section{Results and discussion}

Experiments were carried out at five different longitudinal slopes $(S=0, S=1 / 300, S=1 / 100, S=1 / 50, S=1 / 25)$ with varying discharges. The total number of the experimental set is 35 . Flow regime is subcritical at $S=0$ and $S=1 / 300$, whereas it is supercritical at the remaining slopes. The measured data are given in Table 2. In the Table 2, total, intercepted, bypass flows, the upstream water depth and the Froude numbers for each slope are given. It is observed that there is an increase in the intercepted flow of the grate at higher flow depths by examining Table 2. As the flow increased, the ratio of the intercepted flow to the total flow, namely the efficiency, increased from $40-50 \%$ to $80-90 \%$ (Table 2). Due to the limitations of discharge channels, higher flow rates could not be tested. The flow characteristic of the under grate should not be pressurized.

The discharge value increases as the flow depth on the channel increases for the bars located parallel to the main flow direction. When the flow-efficiency relation is checked for grates used on the highways, the efficiency decreases with increasing flows and depths can be observed (HEC-22 1991; Mc Enroe et al. 1999). This contradiction can be explained by the existence of extending spread and splash over highways gutter. As the depth increases due to increasing spread, smaller ratio of water is observed over the grate. Moreover due to higher speeds, some water splashes over the grate leads to lower ratio of grate interception.

Slope and the Froude number in efficiency

In Eq. 8, the efficiency of a grate is described by nine dimensionless parameters. Among them the Reynolds effects will be neglected due to the fact that the flow will be fully turbulent. Also the term including channel width can be dropped due to the fact that the channel is a wide rectangular channel. In addition, Manning's roughness coefficient and geometric dimensional of the grate are fixed. Further the cross slope is set to zero. Thus the efficiency is described as below for the present study: 
Table 2 Experimental data $(n=0.010)$

\begin{tabular}{|c|c|c|c|c|c|c|}
\hline $\begin{array}{l}Q_{\mathrm{T}} \\
\left(10^{-3}\right. \\
\left.\mathrm{m}^{3} / \mathrm{s}\right)\end{array}$ & $S$ & $\begin{array}{l}Q_{\mathrm{I}} \\
\left(10^{-3}\right. \\
\left.\mathrm{m}^{3} / \mathrm{s}\right)\end{array}$ & $\begin{array}{l}Q_{\mathrm{B}} \\
\left(10^{-3}\right. \\
\left.\mathrm{m}^{3} / \mathrm{s}\right)\end{array}$ & $\begin{array}{l}\varepsilon \\
Q_{\mathrm{I}} / Q_{\mathrm{T}}\end{array}$ & $\begin{array}{l}y_{1} \\
(\mathrm{~m})\end{array}$ & $F$ \\
\hline 0.25 & & 0.12 & 0.13 & 0.480 & 0.00122 & 2.08 \\
\hline 0.89 & & 0.5 & 0.38 & 0.562 & 0.00262 & 2.36 \\
\hline 1.59 & $1 / 25$ & 1.03 & 0.56 & 0.648 & 0.00371 & 2.50 \\
\hline 3.37 & & 2.56 & 0.8 & 0.760 & 0.00583 & 2.69 \\
\hline 4.91 & & 4.02 & 0.9 & 0.819 & 0.00732 & 2.78 \\
\hline 0.38 & & 0.18 & 0.19 & 0.474 & 0.00193 & 1.59 \\
\hline 1.01 & & 0.63 & 0.39 & 0.624 & 0.00348 & 1.75 \\
\hline 1.45 & & 1 & 0.44 & 0.690 & 0.00432 & 1.81 \\
\hline 3.12 & $1 / 50$ & 2.52 & 0.59 & 0.808 & 0.00686 & 1.95 \\
\hline 5.73 & & 4.91 & 0.82 & 0.857 & 0.00990 & 2.06 \\
\hline 7.46 & & 6.5 & 0.96 & 0.871 & 0.01162 & 2.11 \\
\hline 0.41 & & 0.23 & 0.18 & 0.561 & 0.00249 & 1.17 \\
\hline 1.1 & & 0.74 & 0.36 & 0.673 & 0.00451 & 1.29 \\
\hline 1.61 & $1 / 100$ & 1.19 & 0.43 & 0.739 & 0.00567 & 1.34 \\
\hline 2.84 & & 2.34 & 0.5 & 0.824 & 0.00799 & 1.41 \\
\hline 4.27 & & 3.76 & 0.51 & 0.881 & 0.01022 & 1.47 \\
\hline 0.22 & & 0.1 & 0.1 & 0.636 & 0.00239 & 0.67 \\
\hline 0.43 & & 0.3 & 0.1 & 0.721 & 0.00356 & 0.72 \\
\hline 0.82 & & 0.6 & 0.2 & 0.732 & 0.00526 & 0.76 \\
\hline 1.18 & $1 / 300$ & 0.9 & 0.3 & 0.763 & 0.00655 & 0.79 \\
\hline 1.55 & & 1.2 & 0.3 & 0.787 & 0.00772 & 0.81 \\
\hline 2.2 & & 1.8 & 0.4 & 0.836 & 0.00954 & 0.84 \\
\hline 4.27 & & 3.81 & 0.46 & 0.892 & 0.01426 & 0.89 \\
\hline 0.16 & & 0.1 & 0.06 & 0.625 & NA & NA \\
\hline 0.18 & & 0.11 & 0.06 & 0.611 & NA & NA \\
\hline 0.23 & & 0.16 & 0.07 & 0.696 & NA & NA \\
\hline 0.29 & & 0.2 & 0.08 & 0.690 & NA & NA \\
\hline 0.59 & & 0.43 & 0.16 & 0.729 & NA & NA \\
\hline 0.73 & 0 & 0.55 & 0.17 & 0.753 & NA & NA \\
\hline 0.88 & & 0.68 & 0.2 & 0.773 & NA & NA \\
\hline 1.56 & & 1.27 & 0.29 & 0.814 & NA & NA \\
\hline 1.66 & & 1.38 & 0.28 & 0.831 & NA & NA \\
\hline 2.26 & & 1.92 & 0.34 & 0.850 & NA & NA \\
\hline 2.85 & & 2.51 & 0.34 & 0.881 & NA & NA \\
\hline 4.74 & & 4.29 & 0.46 & 0.905 & NA & NA \\
\hline
\end{tabular}

$\varepsilon=f(F, S)$

Table 2 also shows the relation between the total discharge and the efficiency for five different slopes. Two conclusions can be obtained. The first is that as the flow rate increases, the efficiency and intercepted flow ratio also increase. The second is as follows: for a given $Q_{\mathrm{T}}$ the grate efficiency increases as the channel slope approaches to the horizontal slope. Increase in the efficiency as the slope of the channel approaches to horizontal is also demonstrated by Mostkow (1957) and Cromwell et al. (2001). Similar results are also seen in cases where cross slope is different from zero percent. The capacity of grates almost increases as the longitudinal slope approaches to zero (HEC-22 1991; Mc Enroe et al. 1999). Therefore, velocity gets slower over the grate and results in higher efficiency at horizontal slopes.

In order to reach a general statement from Table 2, the procedure given below is followed:

(a) the best fit curve to each data set is determined. Table 3 shows the equation of best fitted curves and their correlation coefficients.

(b) The general character of the equations given in Table 3 has the following characteristic:

$$
\varepsilon=\alpha \mathrm{Q}_{\mathrm{T}}^{\beta}
$$

(c) A new chart is constructed with the coefficients of the equations given in Table 3 . Thus constants $\alpha$ and $\beta$ are plotted against respective slopes and Fig. 9 is obtained.

In the end, the relation between efficiency and the Froude number is demonstrated in Fig. 10. As Froude number increases the efficiency increases for each slope. In

Table 3 Efficiency equations for different slopes

\begin{tabular}{lll}
\hline$S$ & Equation & $r^{2}$ \\
\hline $1 / 25$ & $\varepsilon=0.6023 Q_{\mathrm{T}}^{0.1835}$ & 0.9870 \\
$1 / 50$ & $\varepsilon=0.6163 Q_{\mathrm{T}}^{0.1954}$ & 0.9665 \\
$1 / 100$ & $\varepsilon=0.6658 Q_{\mathrm{T}}^{0.1964}$ & 0.9985 \\
$1 / 300$ & $\varepsilon=0.7587 Q_{\mathrm{T}}^{0.1084}$ & 0.9682 \\
0 & $\varepsilon=0.7821 Q_{\mathrm{T}}^{0.1037}$ & 0.9536 \\
\hline
\end{tabular}

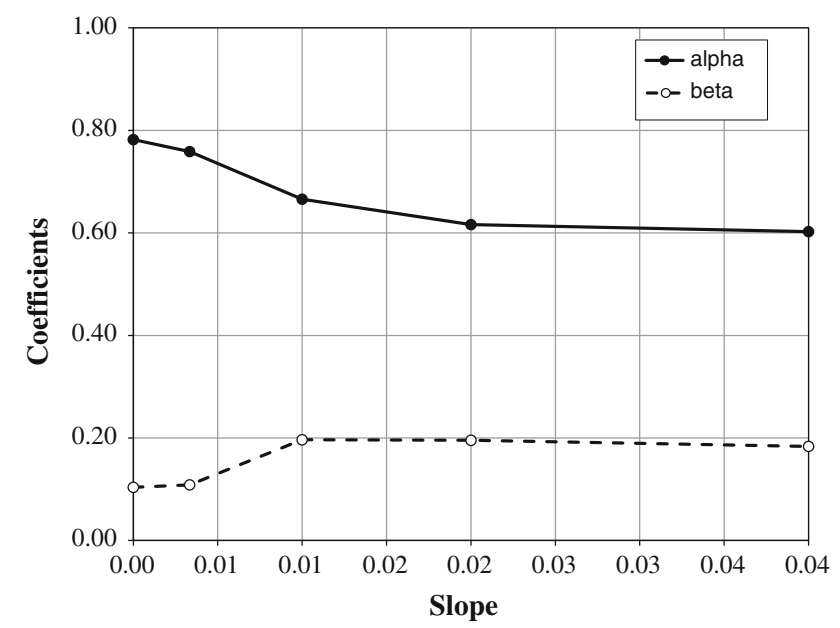

Fig. 9 Variation of coefficients $\alpha$ and $\beta$ (efficiency equation) with slope 


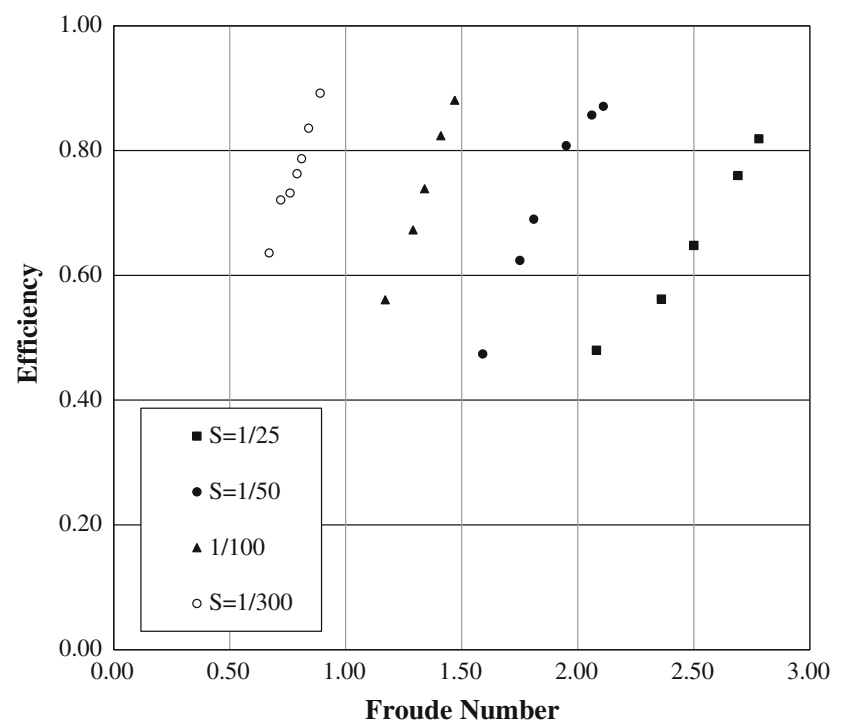

Fig. 10 Variation of efficiency, $\varepsilon$ with the Froude number, $F$

this Figure data are scattered according to slope. However zero slope cannot be inserted. Thus only one set of subcritical flow is showed in the Fig. 10.

\section{Conclusion}

In the present study, a new grated inlet is proposed for small roads which do not have proper rain water collection system. The new designed setup, accordingly realized experiments and collected data are introduced. Several conclusions are derived from both the observations and data analysis:

(a) the upstream depth is too small to apply energy equation.

(b) The efficiency of new grated inlet with zero cross slope is expressed in terms of total discharge and longitudinal slope and It is observed that the grate efficiency is affected by the longitudinal slope of the channel.

(c) The efficiency of the grate gets higher as the longitudinal slope approaches to horizontal.

(d) The grate efficiency also depends on the total flow through the channel. As flow increases in the channel, the efficiency of the grate increases. However, the amount of discharge in the channel cannot be raised more than inlet and discharge channels capacities.

(e) The efficiency can be represented by the Froude number.

It is important to report that due to the limited number of data points an empirical model could not be proposed. However, the range of flow rate, road slope and road dimensions allow us to design a grate for a small road using the charts proposed in this study.

Acknowledgments This study was granted by Middle East Technical University, Office of Scientific Research Coordination (Grant number: BAP-2005-03-03-00-03). The authors acknowledge invaluable support of Prof. Dr. Metin Ger and Dr. Sevgi Tiğrek.

\section{References}

Akan AO (2000) Spread calculation in composite gutter sections. J Transp Eng ASCE 126(5):448-450

ASSHTO (2001) A policy on geometric design of highways and streets. American association of state highway and transportation officials, Washinton, D.C. ISBN: 1-56051-156-7

Beecham S, Mehdi HK, Kandasamy J (2006) Friction factors for spatially varied flow with increasing discharge. J Hydraul Eng ASCE 131:9(792). (8 pages, $251 \mathrm{~KB}$ )

Brown SA, Stein SM, Warner JC (1996) Urban drainage design manual. Hydraulic engineering, circular no. 22, FHWA-SA-96278. US Department of Transportation, Federal Highway Administration, Washington, DC

Brunella S, Hager WH, Minor HE (2003) Hydraulics of bottom racks. J Hydraul Eng 129(1):2-10

Chow VT (1959) Open-channel hydraulics. Mc-Graw Hill, New York

Cromwell C, Rabens C, Kranc SC (2001) Hydraulic performance of grated gutter inlet. In: Phelps D, Shelke G (eds) Bridging the gap: meeting the world's water and environmental resources challenges. State of the practice-proceedings of the World water and environmental resources congress, May 20-24, 2001. The Rosen Plaza Hotel, Orlando, Florida. ASCE, Reston. (978-07844-0569-7 or 0-7844-0569-7)

EPA (2000) Low impact development. US Environmental Protection Agency, Office of Water, Washington DC. (EPA-841-B-00-005)

EPA (2007) Reducing storm water costs through low impact development (LID) strategies and practices. United States Environmental Protection Agency, Washington (EPA 841-F07-006)

FHWA (2001) Urban drainage design manual. Hydraulic engineering, circular no. 22, 2nd edn. US Department of Transportation, Publication No. FHWA-NHI-01-021

Gomez M, Russo B (2005) Comparative study among different methodologies to determine storm sewer inlet efficiency from test data. In: 10th international conference on urban drainage, Copenhagen/Denmark, 21-26 August 2005

Gomez M, Russo B (2009) Hydraulic efficiency of continuous transverse grates for paved areas. J Irrigation Drain ASCE 135(2):225-230

Gomez M, Russo B (2011) Methodology to estimate hydraulic efficiency of drain inlets. Water Manag, ICE, pp 1-10

Guo JCY (2000) Street stormwater storage capacity. J Irrigation Drain ASCE 126(2):119-123

HEC-22 (1991) Urban drainage design manual. US Army Corps of Engineers, Hydrologic Engineering Center, Davis, California

Heggen RJ (1989) Hydraulics of rainwater catchment gutters. In: 4th international conference on rain water cistern systems, section $\mathrm{H}$ : delivery and diversion systems. Manila, Philippines

Kranc SC, Anderson MW (1993) Investigation of discharge through grated inlets. Final Tech Rep, Florida Department of Transportation, USA

Mc Enroe BM, Wade RP, Smith AK (1999) Hydraulic performance of curb and gutter inlets. Final Report no. K-TRAN: KU-99-1 
Mc Ghee TJ (1991) Water supply and sewerage. Mc Graw Hill, Singapore

Mostkow MA (1957) Sur le calcul des grilles de prise d'eau (Theoretical study of bottom type water intake). La Houille blanche, Grenoble, pp 570-580. (12th year)

Munson BC, Young DF, Okishi TH (1998) Fundamentals of Fluid Mechanics, 3rd edn. John Wiley and Sons Inc, Toronto

Nabizadeh R, Mahvi A, Mardani G, Yunesian M (2005) Study on heavy metals in urban runoff. Int $\mathbf{J}$ Environ Sci Technol 1(4):325-333

Noseda G (1955) Operation and design of bottom intake racks. In: Proceedings of the 6th general meeting, international association of hydraulic research, vol 3. The Hague, pp C17-1-C17-11

Pazwash H, Boswell ST (2003) Proper design of inlets and drains for roadways and urban developments. In: Bizier P, DeBarry PA (eds) World water and environmental resources congress 2003, June 23-26, Philadelphia. American Society of Civil Engineers, Reston
Ramamurthy AS, Duc MT, Carballada RB (1989) Open channel flow through transverse floor outlets. J Irrigation Drain 115(2):248-254

Rens KL (2007) Inventory and assessment of Denver, Colorado curb and gutters. J Perform Constr Facil ASCE 21(3):249-254

Righetti M, Lanzoni S (2008) Experimental study of the flow field over bottom intake racks. J Hydraul Eng ASCE 134(1):15-22

Subramanya K (1994) Flow in open channels. Tata McGraw-Hill Publishing Company Limited, New Delhi

Thomas TH (1999) Guttering design for rainwater harvesting development. Working paper no. 50, Technology unit

Thompson D, Fang X, Bahadır GCO (2003) Synthesis of TxDOT storm drain system, report no. 4553-1. Texas Department of Transportation, Lubbock, USA

TSMS (2008) Turkish state meteorological service. (Accessed on November 1st, 2008)

Woo DC, Jones SJ (1974) Hydraulic characteristics of two bicycle safe grate inlet design. Final Tech Rep, report no. FHWA-RD74-77, Federal Highway Administration, Washington (60 pages) 